\title{
Energy security indicators for Pakistan: an integrated approach
}

\begin{abstract}
In this paper, Pakistan's energy security performance based on a study of its energy security index during 1991-2018 is assessed. The assessment, based on an analysis of the energy security and energy policies of Pakistan, focuses on the concepts of "Availability", "Affordability", "Technology", "Governance", and "Environment". Twenty-two indicators, termed the Energy Security Indicators for Pakistan (ESIP), were selected. The ESIP were normalised using the zscore method and weighted based on principal component analysis (PCA). The index analysis revealed that Pakistan's energy security performance decreased between 1991 and 1999, followed by an increase until 2018. A maximum score of 8.36 was attained in 1991, and a minimum of 7.59 was achieved in 1999. During 2000-2018, the performance improved, resulting in a score of 8.29 in 2018. Supply, consumption, and import indicators played a key role in the energy security performance in the studied period.
\end{abstract}

Keyword: Energy security dimensions; Themes; Indicators; Index; Policy 